\title{
Aorto-right ventricular fistula: An early complication of aortic valve replacement
}

\author{
Faten Triki ${ }^{1}$, Sahar Ben Kahla ${ }^{1}$, Rania Hammami ${ }^{1}$, Tarek Sellami ${ }^{1}$, Ahmed Fkih ${ }^{1}$, Dorra Abid ${ }^{1}$, Leila \\ Abid $^{1}$, Mourad Hentati ${ }^{1}$, I med Frikha ${ }^{2}$, Samir Kammoun ${ }^{1}$ \\ 1. Department of Cardiology, Hedi Chaker Hospital, Sfax, Tunisia. 2. Department of Cardiovascular Surgery, Habib \\ Bourguiba Hospital, Sfax, Tunisia.
}

Correspondence: Faten Triki. Address: Department of Cardiology, Hedi Chaker Hospital, El ain Street 0,5 km; 3029 Sfax, Tunisia. Email: trikifaten@yahoo.fr

Received: December 1, 2014

Accepted: December 22, 2014 Online Published: March 26, 2015

DOI : $10.5430 /$ crim.v2n2p55

URL: http://dx.doi.org/10.5430/crim.v2n2p55

\begin{abstract}
The implantation of prosthetic heart valves has been associated with several kinds of complications, but the description of aorto-right ventricle (ARV) fistula as a complication of aortic valve replacement is a very rare finding. We report herein the case of a 56-year-old woman sought care for palpitations two months after prosthetic aortic and mitral valve replacement. Cardiac examination revealed normally audible mechanical sounds with a new loud to-and-fro murmur with continuous precordial thrill. Thyroid function tests were poorly balanced (raised FT4 and lowered TSH). Electrocardiography at admission displayed rapid heart rhythm with atrial fibrillation. Trans-thoracic echocardiography (TTE) revealed left-to-right shunt due to aorto-RV fistula. We discuss then the aetiology, diagnosis and management of this rare para-valvular leakage.
\end{abstract}

\section{Keywords}

Aortic valve surgery, Aorto-right ventricular fistula, Echocardiography

\section{I ntroduction}

The implantation of prosthetic heart valves has been associated with various types of complications which include most commonly infective endocarditis, thromboembolism, hemolysis, pericardial effusion, and valve dysfunction resulting in prosthetic or peri-prosthetic regurgitation and/or obstruction ${ }^{[1]}$. However, the occurrence of aorto-right ventricular (ARV) fistula after prosthetic aortic valve replacement is rare ${ }^{[2]}$. Most of these cases are caused by sinus of Valsalva rupture, endocarditis, and less frequently by trauma or are associated with valve replacement ${ }^{[1,3]}$. We report the case of a 56 -yearold woman who was found to have an ARV fistula, considered as a para-valvular leakage, nearly two months after prosthetic mitral and aortic valve replacement.

\section{Case report}

A 56-year-old woman sought care for decreased exercise tolerance and worsening palpitations. Forty five days earlier, she had undergone both mitral and aortic prosthetic valve replacement with 19 and $21 \mathrm{~mm}$ bileaflet mechanical prosthesis, 
respectively. Early postoperative course was uneventful. Her medical history was significant for rheumatic fever with severe mitral stenosis and regurgitation with severe aortic stenosis and moderate aortic regurgitation with persistent atrial fibrillation. She was taking then furosemide, digoxin, Coumadin and Levothyroxine for hypothyroidism. The patient disclaimed any fever or chills since discharge from surgical facility. Upon initial examination, arterial blood pressure was 110/70 mmHg, heart rate was irregular and rapid of 140 beats per minute and her admittance body temperature was $37^{\circ} \mathrm{C}$. No clinical evidence of congestive heart failure was found. Cardiac examination revealed normally audible mechanical sounds with a new loud to-and-fro murmur with continuous precordial thrill; both had not been present at her last examination.

A laboratory work-up, including a complete blood cell count, electrolyte levels and serum chemistry, was normal unless brain natriuretic peptide level which exceeded $800 \mathrm{ng} / \mathrm{L}$. Hemoglobin was mildly reduced at $11 \mathrm{mg} / \mathrm{dl}$. C reactive protein and procalcitonin values were in normal ranges. International normalized ratio was subtherapeutic at 2,5. Blood cultures were sterile. Thyroid function tests were poorly balanced (raised FT4 at 27,5 ng/l and lowered TSH below 0,01 mIU/l). Electrocardiography at admission displayed rapid heart rhythm with atrial fibrillation at 143 per minute and a single ventricular premature beat. Trans-thoracic echocardiography (TTE) revealed normal functioning of both mitral and aortic prosthetic valve with a slightly impaired left ventricle function (ejection fraction at 45\%). Systolic pulmonary pression was not elevated (25 mmHg). Color Doppler in parasternal long- axis view (mainly when the probe was tilted in order to focus on the right ventricular inflow) (see Figure 1A and 1B) as well as in short axis view (see Figure 2A and 2B) of the aortic annulus valve showed a continuous color- flow jet from the aorta toward the right ventricular cavity. Continuouswave Doppler study demonstrated high velocity of unidirectional left-to-right shunt (4 m/s) (see Figure 3). Subsequently, ultrasound findings were consistent with ARV fistula. Trans-esophageal echocardiography (TEE) was performed to rule out infective endocarditis behind this abnormal communication of $3 \mathrm{~mm}$ between aorta and RV. It showed well-seated prosthetic valves with no vegetation or prosthetic abscess neither aneurysm in the ascending aorta. Given these findings, we carried firstly a proper management of thyroid function which has yielded a relief from dyspnea. The hospital stay remained free of complications. Owing the lack of RV overloads (normal RV size and systolic pulmonary pressure), the shunt volume was believed to be small and ARV fistula was deemed symptomless in agreement with the surgeons. Our patient was symptom free at hospital discharge. During 12 months of late follow up, she had no recurrence of complaints and echocardiographic control demonstrated no change in the ARV fistula.

Figure 1A (left). Color Doppler in parasternal long- axis view showing the fistula (arrow) between aorta and right ventricular cavity. Figure 1B (right). Color Doppler in parasternal long- axis view when probe was tilted in order to focus on the right ventricular inflow showing a continuous color-flow jet from the aorta toward the right ventricular cavity.

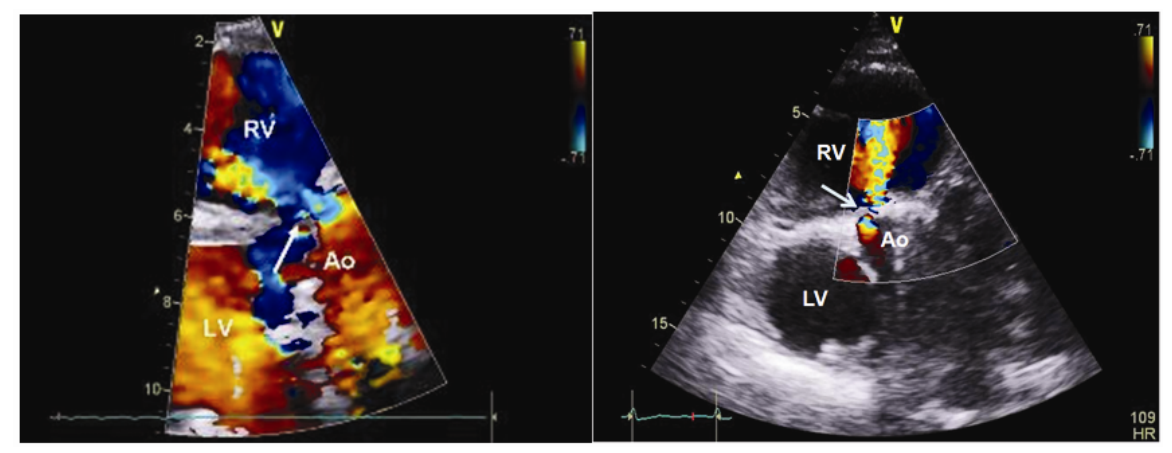

Figure 2A (left). Two-dimensional and Color Doppler in parasternal short-axis view showing the fistula (arrow) between aorta and right ventricular cavity. Figure 2B (right). Color Doppler in parasternal shortaxis view showing the fistula (arrow) between aorta and right ventricular cavity.

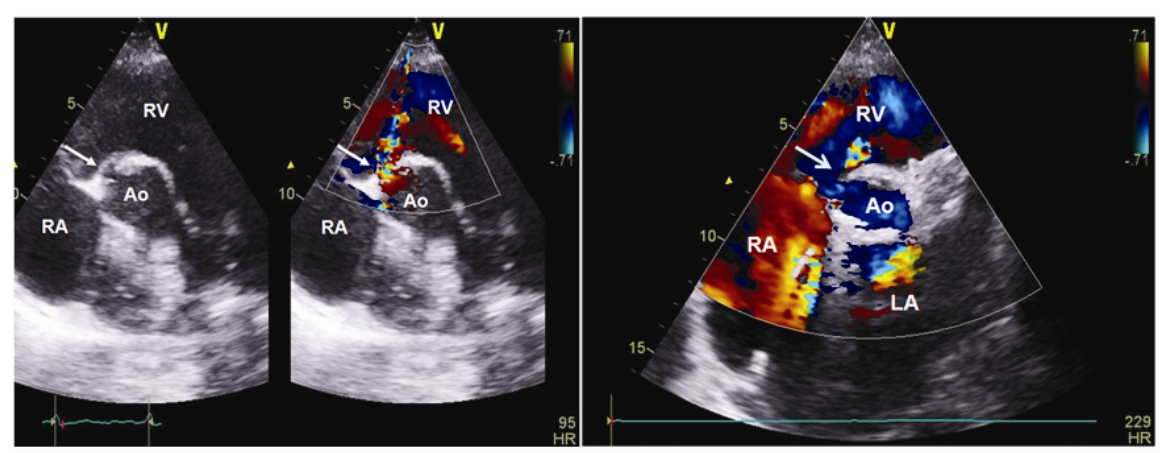


Figure 3. Continuous-wave Doppler study demonstrated highvelocity of unidirectional left-to-right shunt $(4 \mathrm{~m} / \mathrm{s})$

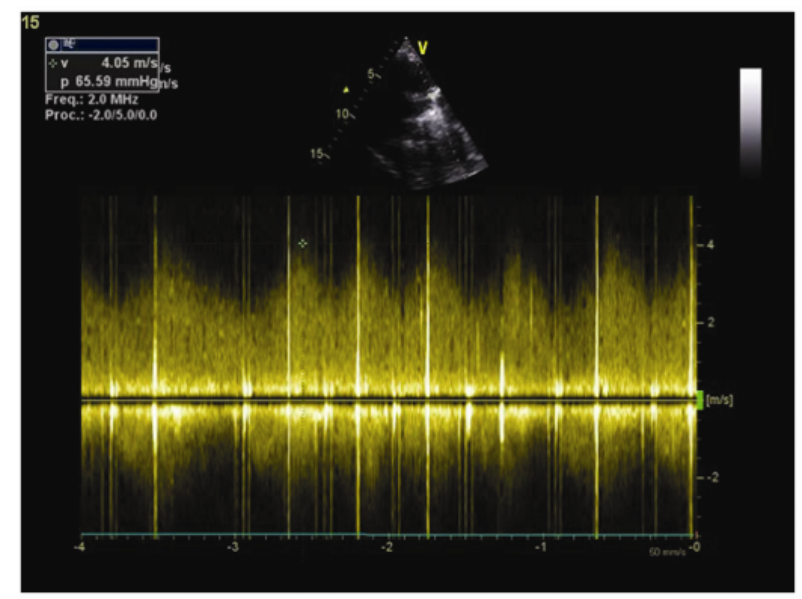

\section{Discussion}

ARV fistulas are defined anatomically as defects of the aortic wall in the area above the right coronary cusp, where it separates aorta and the right ventricular outflow tract ${ }^{[4]}$. In general, ARV fistulas have been described to occur because of rupture of congenital and acquired sinus of Valsalva aneurysms. Although rare, blunt trauma to the chest, penetrating chest trauma, aortic dissection, high ventricular septal defect repair and aortic valve surgery have been reported to result in ARV fistula ${ }^{[5,6]}$. Because ARV fistulas are uncommon, the true incidence is unknown. According to a series of 310 patients with aortic valve replacement and found only 1 case of fistula from the aorta to the right atrium as well as the RV, thereby the incidence seems to be less than $0.5 \%{ }^{[6]}$. Often, ARV fistulas are a complication of penetrating chest trauma ${ }^{[7,8]}$ or most typically of infective endocarditis ${ }^{[9,10]}$. In the other hand, ARV fistula may follow a rupture of a congenital aortic sinus aneurysm ${ }^{[11]}$.When occurring in infective endocarditis, ARV fistula is associated with gloomy prognosis because of higher mortality (55\% according to a series of 346 consecutive cases of infective endocarditis) ${ }^{\text {[12] }}$. This complication is encountered in $2 \%$ in native valve endocarditis ${ }^{[9,13]}$ and $3 \%$ in prosthetic valve endocarditis ${ }^{[14]}$. Iatrogenic origin of ARV fistulas are increasingly reported, mainly with the development of interventional procedures. Indeed, ARV fistula may follow either surgical aortic valve replacement ${ }^{[1,15]}$ or percutaneous aortic valve implantation (TAVI) ${ }^{[16]}$. Several mechanisms may lead to cardiac shunts during aortic valve surgery including unintentional injury to the membranous septum sustained during dissection below the noncoronary cusps, perivalvular damage attributable to improper retraction and excessive and aggressive debridement of bulky areas of calcification from the aortic annulus [5-17] and/or pseudo-aneurysm formation secondary to degenerative changes at the aortotomy line and the pseudo-aneurysm's eventual rupture into the $\mathrm{RV}^{[1]}$. Lorenz et al. proposed ischemic necrosis because of inappropriate suturing of the mechanical valve if the membranous portion of the ventricular septum is included in the prosthetic valve suture line ${ }^{[5]}$. In our case, ARV fistula occurred early after aortic valve replacement and intraoperative examination of the native aortic valve demonstrated heavily calcified areas.

ARV fistula may cause several clinical presentations depending on aetiology, size of shunt and its natural course (acute or chronic onset) ${ }^{[18]}$. Small leaks have a benign prognosis with small shunt volume and limited cardiac overload. Thus, patients may be thoroughly asymptomatic and ARV fistula is usually diagnosed during routine follow up appointment. Typically, a diastolic or continuous murmur is heard over the precordium, but it may be hard sometimes to perceive this murmur in patients with mechanical valves. Larger fistulas may lead to congestive heart failure; right ventricular failure is the ultimate expression which is associated with poor outcome and death ${ }^{[19]}$. Hence, medical treatment, including mainly diuretics, remains palliative and sometimes ineffective to relieve symptoms of heart failure in large fistulas ${ }^{[20]}$. Haemolysis (with anaemia and icterus) may worsen the clinical course in these cases. ARV fistula may also mimic 
uncommonly acute coronary syndrome ${ }^{[21]}$. Fever may be found and this promotes to bring out infectious origin ARV fistulas.

In our case, neither symptoms nor signs sustained the hypothesis of endocarditis as cause of ARV fistula. TEE is more useful rather than TTE to assess deeply valve function and to define accurately shunt morphology and volume. Currently, three-Dimensional trans-thoracic echocardiography is increasingly widespread and provides therefore better special orientation combined with color flow mapping to identify promptly fistulas ${ }^{[10]}$. Diagnosis may also be made by cardiac catheterization, magnetic resonance imaging or multi-slice computed tomography may demonstrate ARV fistula ${ }^{[22]}$. Since natural history of ARV fistula after aortic valve surgery is weakly studied, careful follow up of patients is mandatory. No documented case of spontaneous closure was reported and shunts in ARV fistula are indeed characterized by their propensity to increase in size overtime ${ }^{[23]}$. ARV fistulas are known to be highly morbid leading often to heart failure as major complication and mortality exceeded $40 \%$ when associated to infective endocarditis ${ }^{[10,13]}$.

Conventionally, paravalvular leaks are treated by open heart surgery under cardiopulmonary bypass; however this redo surgery is very risky and may carry several serious complications because of critically instable patients who are poor surgical candidates (depressed left ventricular function and pulmonary hypertension) ${ }^{[3,24,25]}$. Surgery is indicated according to size of shunt and clinical characteristics of the patient. Owing to major advances in interventional cardiology in recent decades, effective closure of ARV fistula is now performed percutaneously by many devices with 3-dimensional guidance. We mention for instance PDA Rashkind occluder, the Amplatzer Duct Occluder, the Amplatzer ASD or PFO Occluder, the Sideris buttoned device, different types of coils and more recently, the Amplatzer Plug ${ }^{[17,26,27]}$.

Our patient experienced exertional dyspnea and palpitations because of poor balance in her thyroid function and proper medical management with diuretics allowed a major and rapid improvement in her clinical state. We believe that a small ARV fistulous communication with high velocity should be carefully and regularly followed-up to ensure durable recovery after discharge. During 12 months of postoperative follow up, our patient did not report any symptoms and ARV fistula did not change.

In summary, ARV fistula is an exceedingly rare finding after aortic valve replacement. Diagnosis is usually suspected by cardiac examination which reveals peculiar heart murmur and confirmed by echocardiography which allows a precise definition of the shunt. Management depends deeply on clinical presentation and the presence of pulmonary hypertension. Surgical closure remains the gold standard to treat effectively ARV fistula however, accurate percutaneous procedure may be encouraged because of high morbidity and mortality of a redo surgery. In our case, we opted for medical treatment because of small shunt, its high velocity and the presence of non-cardiac cause which was unbalanced thyroid function. Endocarditis prophylaxis and at least yearly follow up are always recommended for patients with ARV fistula occurring after aortic valve replacement.

\section{References}

[1] Roy D, Saba S, Grinberg I, et al. Aorto-right ventricular fistula: a late complication of aortic valve replacement. Tex Heart Inst J. 1999; 26: 140-2. PMid:10397439

[2] Najib MQ, Ng D, Vinales KL, et al. Aorto-right ventricular fistula: a complication of aortic valve replacement. Ann Thorac Cardiovasc Surg. 2012; 18(1): 64-7. PMid:21959192 http://dx.doi.org/10.5761/atcs.cr.11.01671

[3] Miller DL, Morris JJ, Schaff HV, et al. Reoperation for aortic valve periprosthetic leakage: identification of patients at risk and results of operation. J Heart Valve Dis. 1995; 4: 160-165. PMid:8556176

[4] Walpot J, Klazen C, Hokken R, et al. Aorto-right ventricular fistula as an occasional finding. Eur J Echocardiogr. 2005 Jan; 6(1): 65-6. PMid:15664555 http://dx.doi.org/10.1016/j.euje.2004.08.009

[5] Lorenz J, Reddy CV, Khan R, et al. Aortico-right ventricular shunt following aortic valve replacement. Chest. 1983; 83: 922-5. PMid:6851697 http://dx.doi.org/10.1378/chest.83.6.922 
[6] Jackson DH Jr, Murphy GW, Stewart S, et al. Delayed appearance of left-to-right shunt following aortic valvular replacement, report of two cases. Chest. 1979; 75: 184-6. PMid:421554http://dx.doi.org/10.1378/chest.75.2.184

[7] Rudstad DG, Hopeman AR, Murr PC, et al. Aortocardiac fistula with aortic valve injury from penetrating trauma. J Trauma. 1986; 26(3): 266-70.

[8] Siavelis HA, Marsan R, Marshall WJ, et al. Aortoventricular fistula secondary to blunt trauma: a case report and review from the literature. J Trauma. 1997; 43(4): 713-5.

[9] Baumgartner FJ, Omari BO, Robertson JM, et al. Annular abscesses in surgical endocarditis: anatomic, clinical and operative features. Ann Thorac Surg. 2000; 70: 442-7.

[10] Patel V, Fountain A, Guglin M, et al. Three-dimensional transthoracic echocardiography in identification of aorto-right atrial fistula and aorto-right ventricular fistulas. Echocardiography. 2010 Oct; 27(9): E105-8. PMid:20584055http://dx.doi.org/10.1111/j.1540-8175.2010.01225.x

[11] Rashkind JW, Norwicki ER, Aberdeen E, et al. Congenital left aortic sinus-left ventricle fistula and review of aortocardiac fistulas. Ann Thorac Surg. 1977; 23(4): 378-88.

[12] Anguera I, Quaglio G, Miro JM, et al. Aortocardiac fistulas complicating infective endocarditis. Am J Cardiol 2001; 87(5): 652-4.

[13] Anguera I, Miro JM, Evangelista A, et al. Periannular complications in infective endocarditis involving native aortic valves. Am J Cardiol. 2006; 98: 1254-60. PMid:17056342http://dx.doi.org/10.1016/j.amjcard.2006.06.016

[14] Anguera I, Miro JM, San Roman JA, et al. Periannular complications in infective endocarditis involving prosthetic aortic valves. Am J Cardiol. 2006; 98: 1261-68. PMid:17056343 http://dx.doi.org/10.1016/j.amjcard.2006.05.066

[15] Badak O, Akdeniz B, Aslan O, et al. Rare complication of aortic valve replacement: Aorto-right atrial fistula. Anadolu Kardiyol Derg. 2003; 3: 373. PMid:14675898

[16] Pilgrim T, Meier B, Wenaweser P. Aorto-right ventricular fistula after transfemoralortic valve implantation. J Invasive Cardiol. 2010; 22: E30-E31. PMid:20124600

[17] Eng MH, Garcia JA, Hansgen A, et al. Percutaneous closure of a para-prosthetic aorto-right ventricular fistula. Int J Cardiol. 2007; 118: e31-4. PMid:17383747 http://dx.doi.org/10.1016/j.ijcard.2006.12.004

[18] Karapinar H, Kucukdurmaz Z, Gumrukcuoglu H, et al. Treatment strategies for aorta-right ventricular fistula associated with aortic and/or mitral valve replacements: a case report with a review of the literature; Post KardiolInterw. 2011; 7, 2 (24): 182-4

[19] Pate G, Zubaidi AA, Chandavimol M, et al. Percutaneous closure of prosthetic paravalvular leaks: case series and review. Catheter Cardiovasc Interv. 2006; 68: 528-33. PMid:16969856http://dx.doi.org/10.1002/ccd.20795

[20] Archer TP, Mabee SW, Baker PB, et al. Aorto-left atrial fistula: a reversible cause of acute refractory heart failure. Chest; 1997; 111: 828-31. PMid:9118732 http://dx.doi.org/10.1378/chest.111.3.828

[21] Amabile N, Gil JM, Sarran A. Aorto-right ventricular fistula presenting 10 years after aortic surgery as an acute coronary syndrome. Arch Cardiovasc Dis. 2009 Feb; 102(2): 153-4. PMid:19303583http://dx.doi.org/10.1016/j.acvd.2008.08.003

[22] Jiayi Li, Haichang Wang, Minwen Zheng. Diagnosis of aortic-right ventricular tunnel by dual-source computed tomography. European Journal of Cardio-thoracic Surgery. 2011; 39: 609. PMid:20832331 http://dx.doi.org/10.1016/j.ejcts.2010.07.033

[23] Tiwari K, Salvati A, Summa M, et al. Aorta-to-right ventricular outflow tract fistula with coronary cusp prolapse. Asian Cardiovascular \& Thoracic Annals. 2012; 21(2): 193-5. PMid:24532619 http://dx.doi.org/10.1177/0218492312449011

[24] Jindani A, Neville EM, Venn G, et al. Paraprosthetic leak: a complication of cardiac valve replacement. J Cardiovasc Surg (Torino). 1991; 32: 503-8.

[25] Akins CW, Bitondo JM, Hilgenberg AD, et al. Early and late results of the surgical correction of cardiac prosthetic paravalvular leaks. J Heart Valve Dis. 2005; 14: 792-99. PMid:16359061

[26] Lu TL, Beregi JP, Rey C, et al. Percutaneous Closure of an Aorto-right Ventricular Fistula with an Amplatzer Plug. J VascIntervRadiol. 2011 Jan; 22(1): 100-1. PMid:21195903 http://dx.doi.org/10.1016/j.jvir.2010.09.019

[27] Dussaillant GR, Romero L, Ramirez A, et al. Successful percutaneous closure of paraprostheticaorto-right ventricular leak using the Amplatzer duct occluder. Catheter CardiovascInterv. 2006; 67: 976-80. PMid:16649242 http://dx.doi.org/10.1002/ccd.20720 